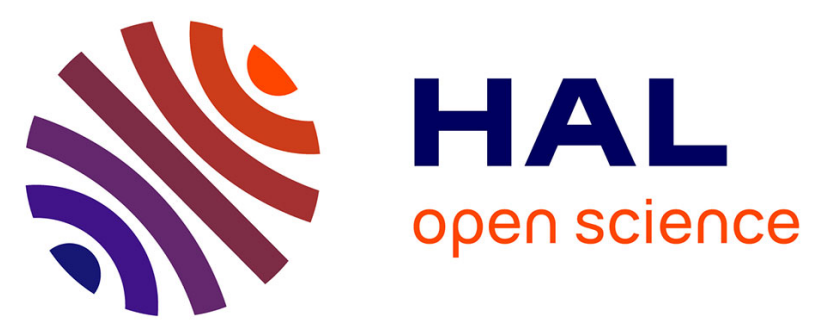

\title{
Development of a supercritical fluid chromatography method with ultraviolet and mass spectrometry detection for the characterization of biomass fast pyrolysis bio oils
}

Julien Crepier, Agnès Le Masle, Nadège Charon, Florian Albrieux, Sabine

Heinisch

\section{To cite this version:}

Julien Crepier, Agnès Le Masle, Nadège Charon, Florian Albrieux, Sabine Heinisch. Development of a supercritical fluid chromatography method with ultraviolet and mass spectrometry detection for the characterization of biomass fast pyrolysis bio oils. Journal of Chromatography A, 2017, 1510, pp.73-81. 10.1016/j.chroma.2017.06.003 . hal-01574810

\author{
HAL Id: hal-01574810 \\ https://hal.science/hal-01574810
}

Submitted on 9 Nov 2017

HAL is a multi-disciplinary open access archive for the deposit and dissemination of scientific research documents, whether they are published or not. The documents may come from teaching and research institutions in France or abroad, or from public or private research centers.
L'archive ouverte pluridisciplinaire HAL, est destinée au dépôt et à la diffusion de documents scientifiques de niveau recherche, publiés ou non, émanant des établissements d'enseignement et de recherche français ou étrangers, des laboratoires publics ou privés. 


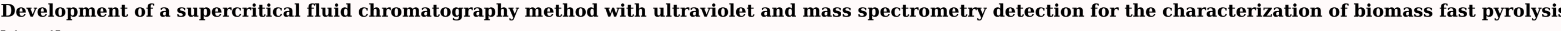

bio oils

Julien Crepier

Agnès Le Masle ${ }^{\mathrm{a}, *}$

agnes.le-masle@ifpen.fr

Nadège Charon

Florian Albrieux

Sabine

a'IFP Energies nouvelles, Rond-point de l'échangeur de Solaize, BP 3, 69360 Solaize, France

buniversité de Lyon, CNRS, Université Claude Bernard Lyon 1, Ens de Lyon, Institut des Sciences Analytiques, UMR 5280, 5 rue de la Doua, F-69100 Villeurbanne, France

${ }^{*}$ Corresponding author.

\section{Abstract}

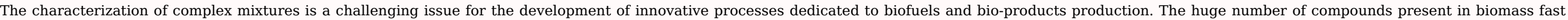

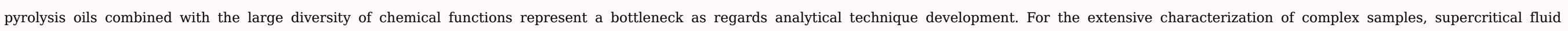

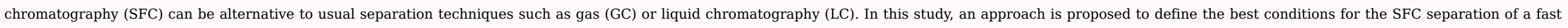

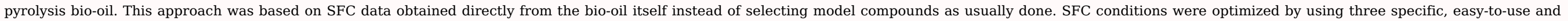

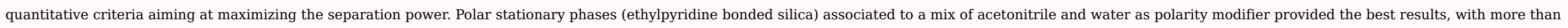
120 peaks detected in SFC-UV.

Keywords: Supercritical fluid chromatography; Mass spectrometry; Bio-oil; Fast pyrolysis; Complex sample

\section{Introduction}

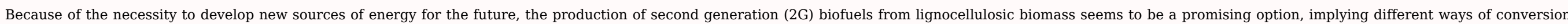

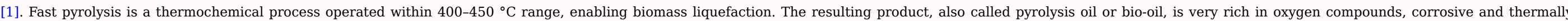

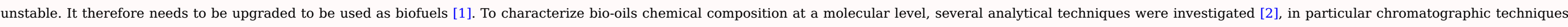

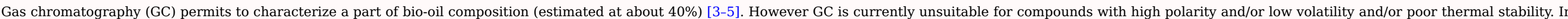

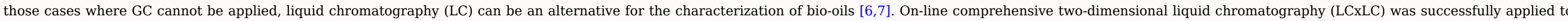

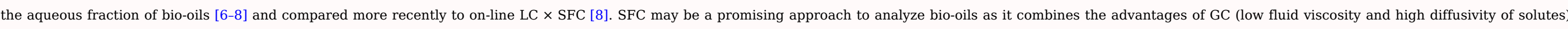

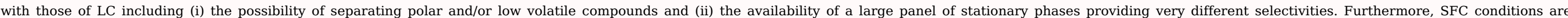
expected to be soft with a usual temperature range between 30 and $60^{\circ} \mathrm{C}$, compatible with most of the compounds present in bio-oils.

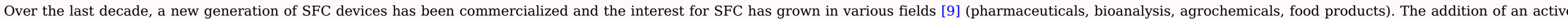

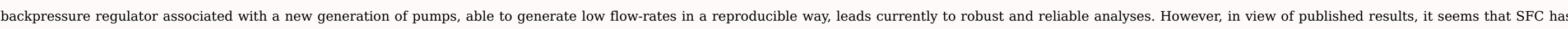




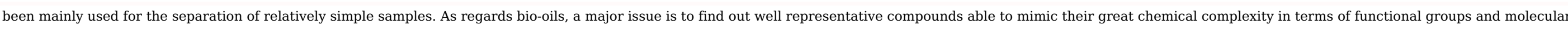

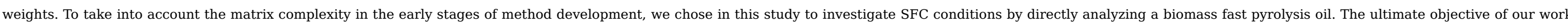

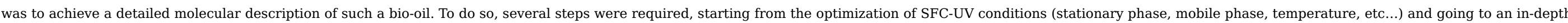

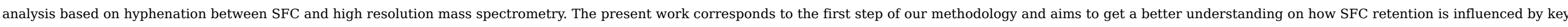

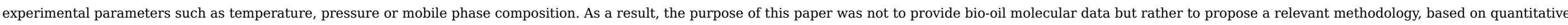

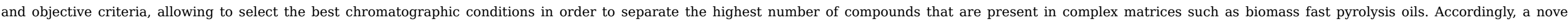

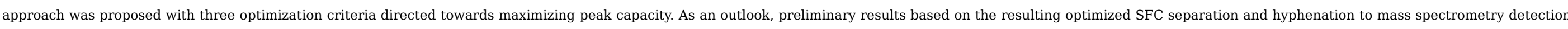
are illustrated in order to point out the potential of this technique for bio-oil analysis.

\section{Materials and methods}

\subsection{Chemicals and samples preparation}

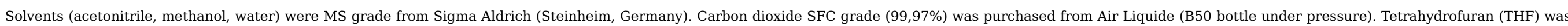
purchased from VWR (Fontenay sous bois, France). The fast pyrolysis bio-oil was obtained from conifer sawdust, provided by IFP Energies nouvelles. The sample was diluted in THF (1/5 w/w) before analysis.

\subsection{Instrumentation and chromatographic conditions}

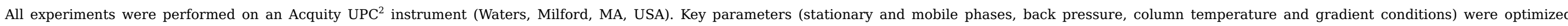

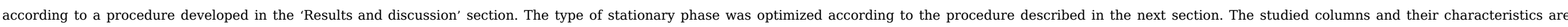

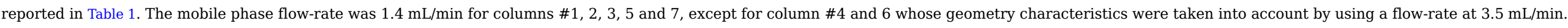

Table 1 Characteristics of the columns investigated in this study.

\begin{tabular}{|c|c|c|c|c|c|c|c|}
\hline Column number & Column name & Manufacturer & Stationary phase chemistry & $\mathrm{d}_{\mathrm{c}}^{\mathrm{a}}(\mathrm{mm})$ & $\mathrm{L}_{\mathrm{c}}^{\mathrm{b}}(\mathrm{cm})$ & $\mathrm{d}_{\mathrm{p}}^{\mathrm{c}}(\mu \mathrm{m})$ & $\mathrm{L}_{\mathrm{c}} / \mathrm{d}_{\mathrm{p}}$ \\
\hline 1 & Acquity $\mathrm{UPC}^{2} \mathrm{BEH}$ & Waters & Unbonded silica & 3.0 & 10 & 1.7 & 5.88 \\
\hline 2 & Acquity UPC $2 \mathrm{HSS}_{18} \mathrm{SB}$ & Waters & $\mathrm{C}_{18}$ & 3.0 & 10 & 1.8 & 5.55 \\
\hline 3 & Acquity $\mathrm{UPC}^{2} \mathrm{BEH} 2$-EP & Waters & Ethyl Pyridine & 3.0 & 10 & 1.7 & 5.88 \\
\hline 4 & Luna Cyano & Phenomenex & Cyanopropyl & 4.6 & 15 & 3.0 & 5.00 \\
\hline 5 & Acquity UPC² BEH RP18 Shield & Waters & Polar embedded $\mathrm{C}_{18}$ & 3.0 & 10 & 1.7 & 5.88 \\
\hline 6 & Nucleodur Polartech & Macherey-Nagel & Polar embedded $\mathrm{C}_{18}$ & 3.0 & 10 & 2.5 & 4.00 \\
\hline 7 & Acquity UPC² CSH Fluorophényl & Waters & Fluorophenyl & 3.0 & 10 & 1.7 & 5.88 \\
\hline
\end{tabular}

a Column internal diameter.

b Column length.

c Particle diameter.

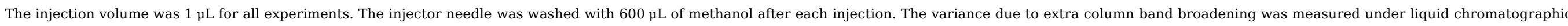

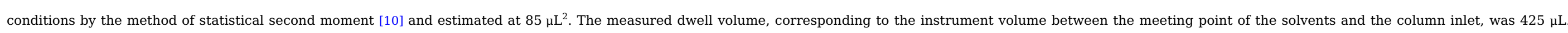

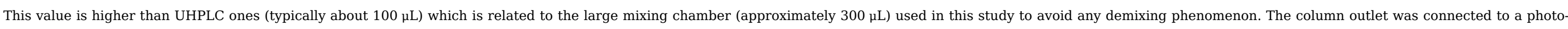




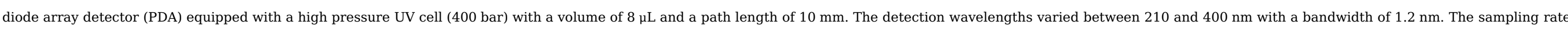
was set at $40 \mathrm{~Hz}$. The instrument was controlled by Empower 3 software (Waters).

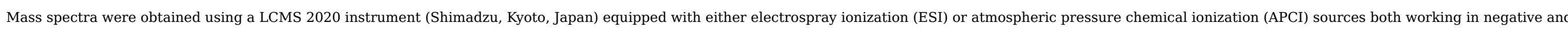

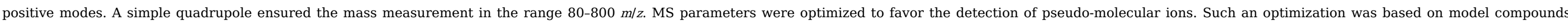

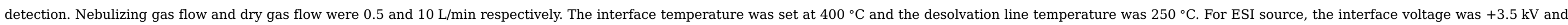
$-5 \mathrm{kV}$ in positive and negative ion modes respectively. For APCI source, the corona current in negative mode and positive modes were respectively $80 \mu \mathrm{A}$ and $70 \mu \mathrm{A}$.

\section{Results and discussion}

\subsection{Methodology for optimizing key SFC parameters}

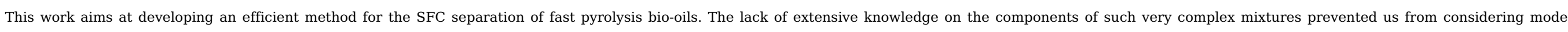

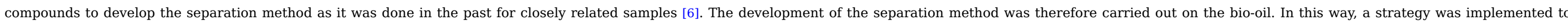

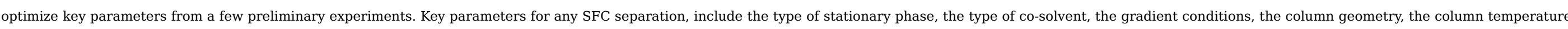

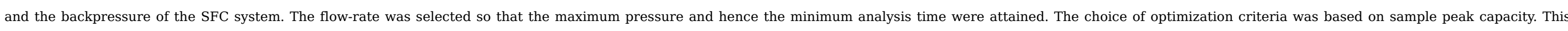

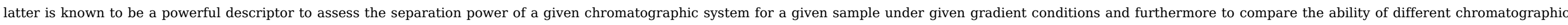
systems to separate the components of this sample. The sample peak capacity, $\mathrm{n}_{\mathrm{grad}}$, in gradient elution was defined by Dolan et al. [11] as

$n_{\text {grad }}=\frac{t_{n}-t_{1}}{w}$

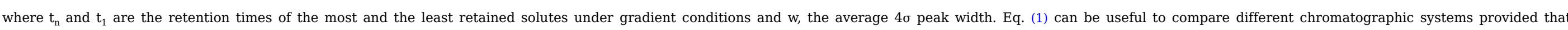

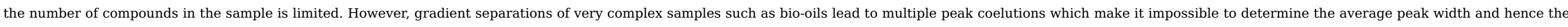

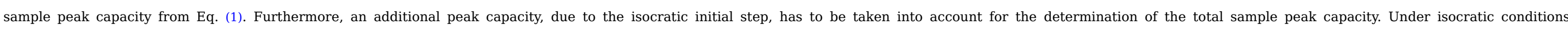
(corresponding to the initial composition), the sample peak capacity, $\mathrm{n}_{\text {iso, }}$ is given by Eq. (2) defined as [11]

$$
n_{i s o}=\frac{\sqrt{N}}{4} \times \ln \frac{1+k_{n, i s o}}{1+k_{1, i s o}}
$$

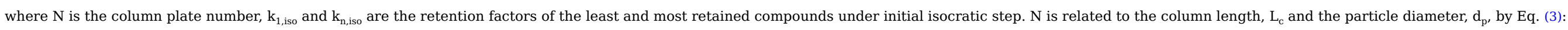

$$
N=\frac{L_{c}}{h \times d_{p}}
$$

where $\mathrm{h}$ is the reduced column plate height.

35 years ago, Snyder and co-workers developed the semi-empirical Linear Solvent Strength Theory (LSST) based on a linear relationship between the logarithm of the solute retention factor and the time:

$$
\log (k)=\log \left(k_{i}\right)-b \frac{\left(t-t_{\text {delay }}\right)}{t_{0}}
$$

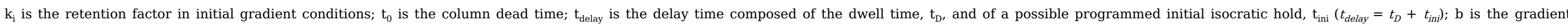
steepness given by

$b=S \times s$

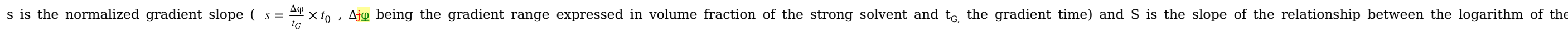
solute retention factor and the volume fraction of the strong solvent:

$\log (k)=\log \left(k_{0}\right)-S \varphi$ 
$\mathrm{k}_{0}$ being the solute retention factor in the weak solvent and $\varphi$, the volume fraction of the strong solvent, B.

According to LSST and considering (i) an average $\mathrm{S}$ value and (ii) high $\mathrm{k}_{\mathrm{i}}$ values for all solutes, the following equation can be derived from Eq. (1) [11]:

$$
n_{\text {grad }}=2.303 S\left(\varphi_{n, \text { grad }}-\varphi_{1, \text { grad }}\right) \times \frac{1}{1+2.303 b} \times \frac{\sqrt{N}}{4}
$$

where $\varphi_{\mathrm{n}, \text { grad }}$ and $\varphi_{1, \text { grad }}$ are the composition at elution of the most and least retained compounds under gradient conditions.

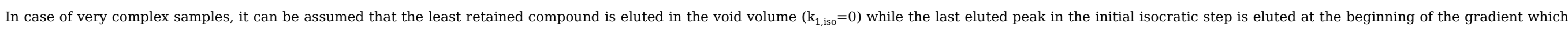
means that $\varphi_{1, \text { grad }}$ corresponds to the initial composition $\varphi_{\text {ini }}$ and that

$k_{n, i s o}=\frac{t_{\text {delay }}}{t_{0}}$

From Eqs. (2), (3), (8) and (9), the resulting equation for the total sample peak capacity can be expressed as

$$
n=\frac{1}{4} \sqrt{\frac{L_{c}}{h d_{p}}}\left(\ln \left(1+\frac{t_{\text {delay }}}{t_{0}}\right)+2.303 S\left(\varphi_{n, \text { grad }}-\varphi_{\text {ini }}\right) \times \frac{1}{1+2.303 b}\right)
$$

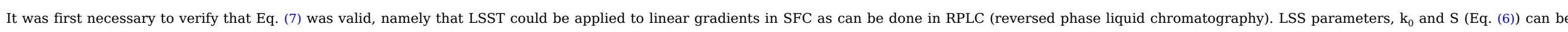

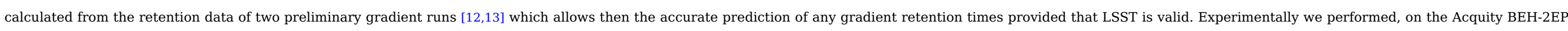

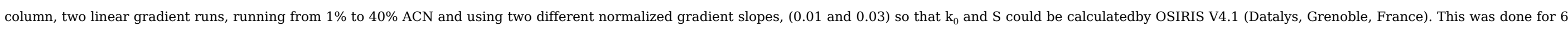

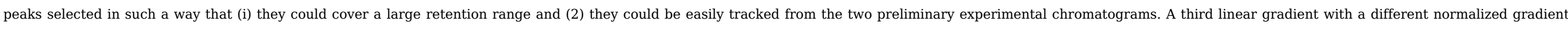

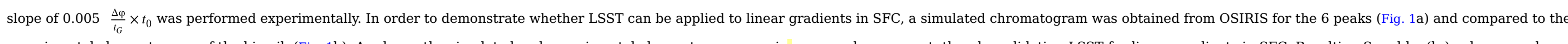

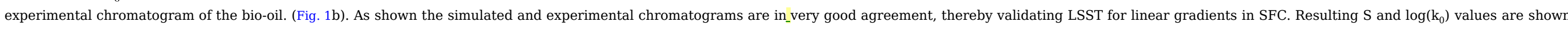

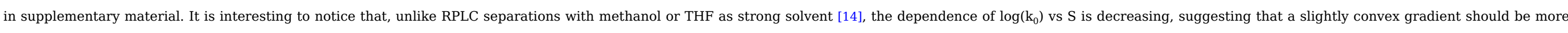

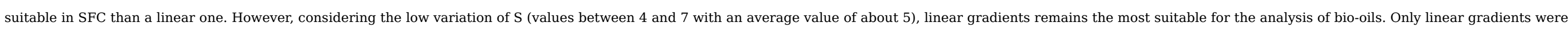
therefore evaluated in the rest of this study. A similar trend (not shown) was observed with chromatographic systems which were studied in this work.

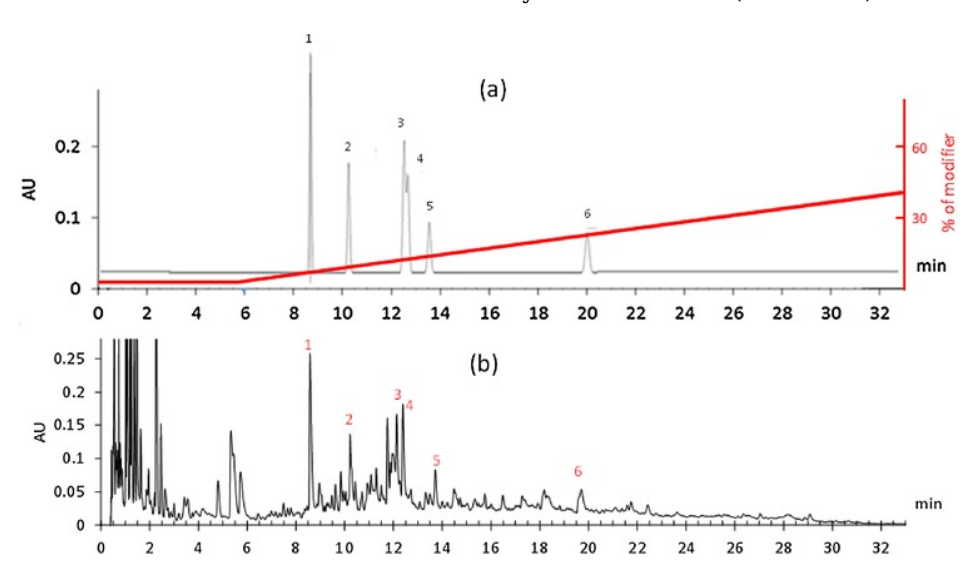

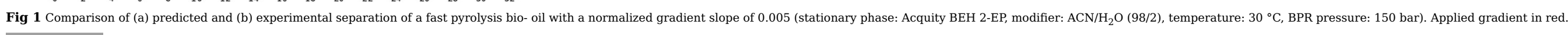
alt-text: Fig 1

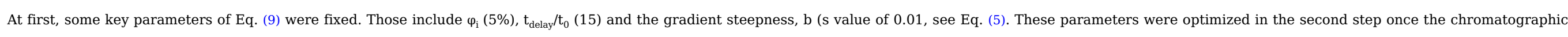

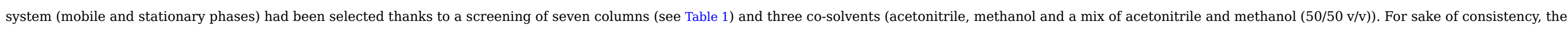




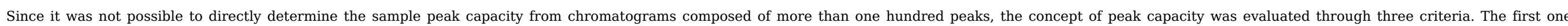

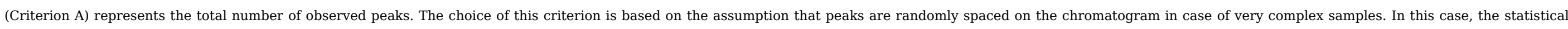

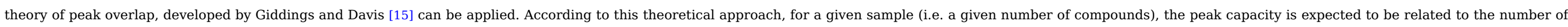

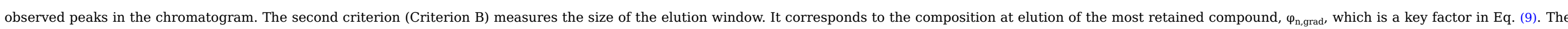

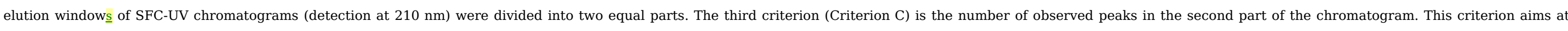

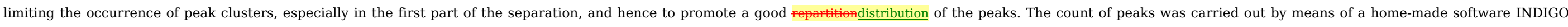

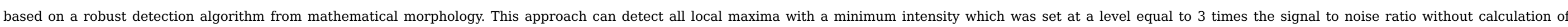

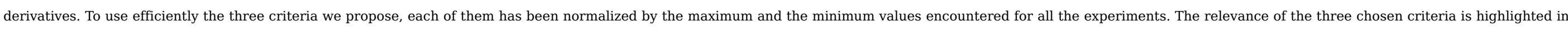

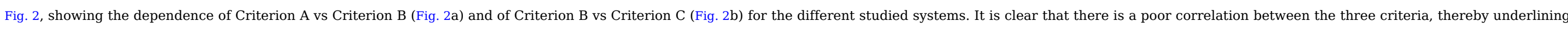

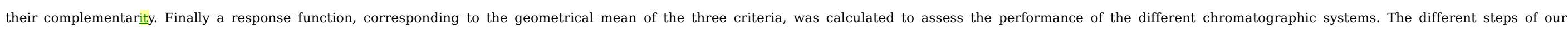
methodology are illustrated in Fig. 3.
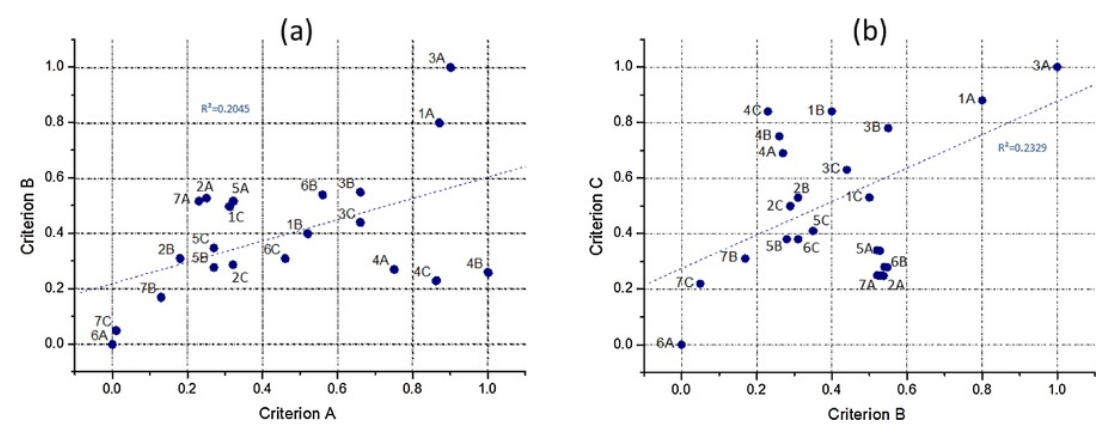

Fig. 2 Dependence of (a) criterion B vs criterion A and (b) criterion C vs criterion B for the studied chromatographic systems identified by combination of number (see Table 1) and letter (A: ACN, B: mix ACN/MeOH 50/50, C: MeOH). alt-text: Fig. 2

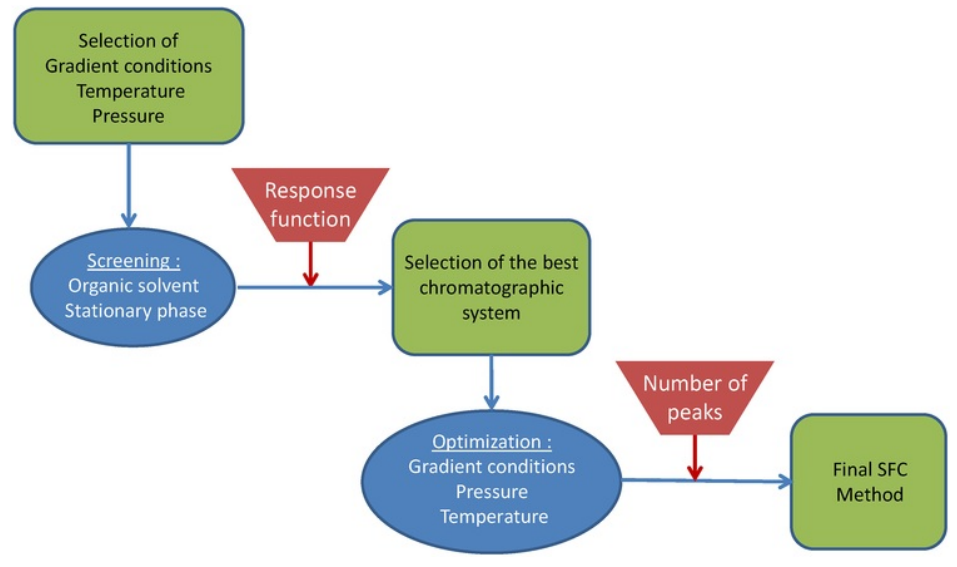

Fig. 3 Methodology for optimizing SFC key parameters. 


\subsection{Screening of mobile and stationary phases}

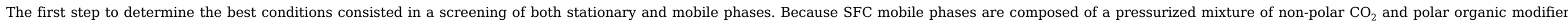

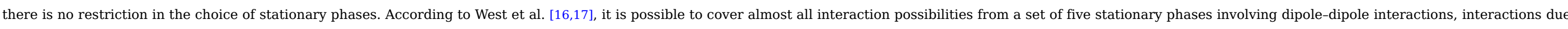

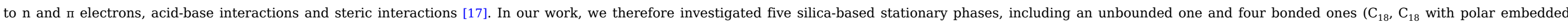

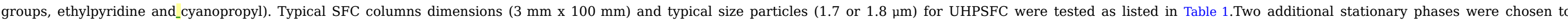

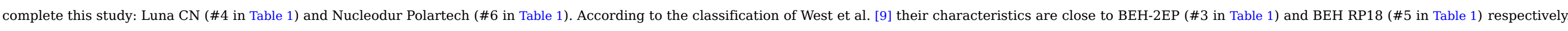

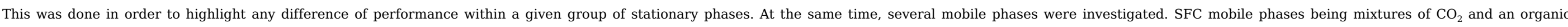

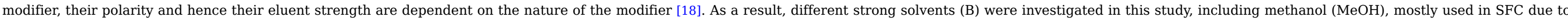

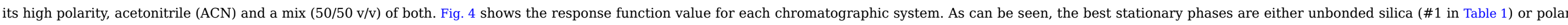

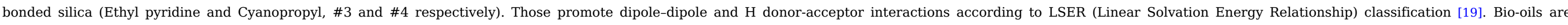

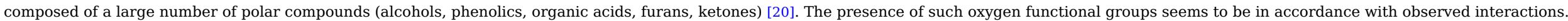

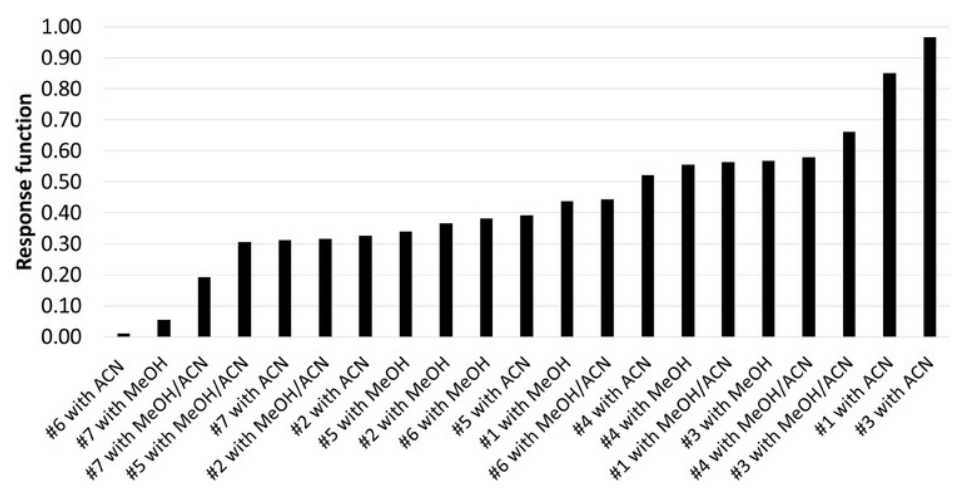

Fig. 4 Response function values for the different studied chromatographic systems. The studied columns are numbered as in Table 1 .

alt-text: Fig. 4

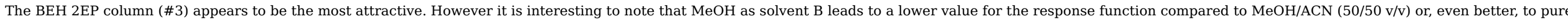

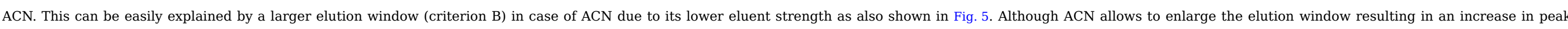

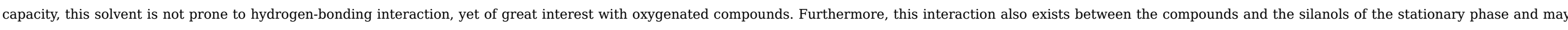

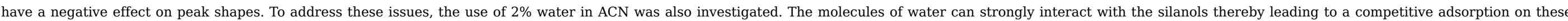

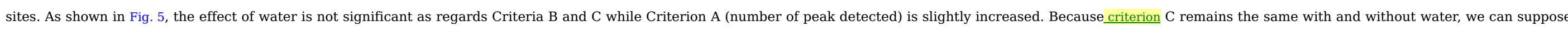

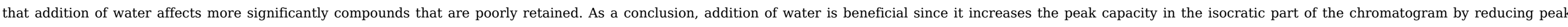
broadening. 


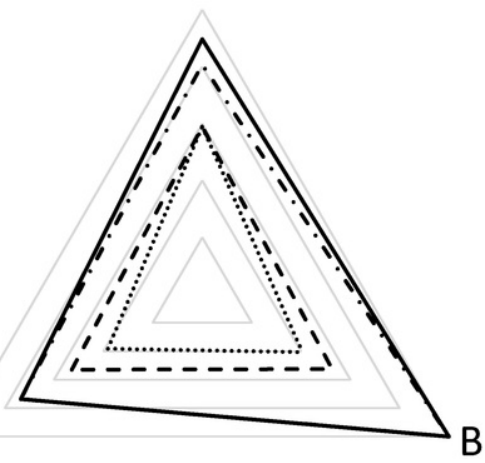

Fig. 5 Evolution of Criteria A, B and C using the Acquity BEH-2EP column (\#3 in Table 1) depending on the strong solvent B: Acetonitrile (- . - -), Methanol (w......), Acetonitrile / Methanol (50/50; v/v) (- - -), Acetonitrile/Water (98/2; v/v) (—). alt-text: Fig. 5

Similarly, others additives were tested (i.e. trifluoroacetic acid, ammonium acetate, diethanolamine and formic acid) but none of them had a significant impact on the number of peaks detected.

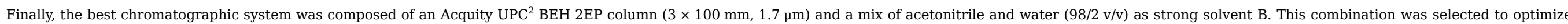
the other key parameters.

\subsection{Optimization of mobile phase composition}

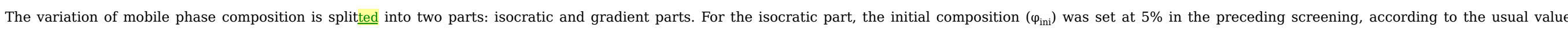

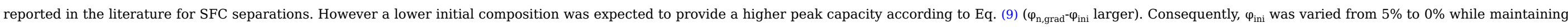

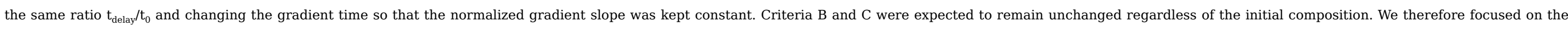

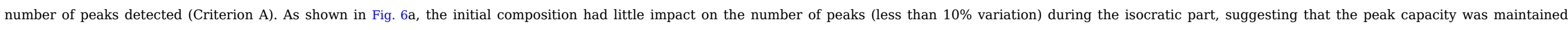

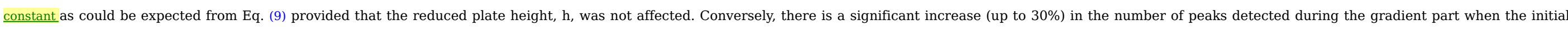

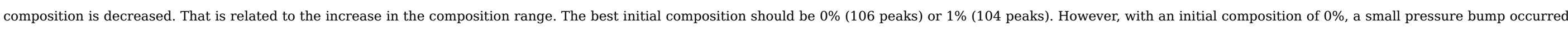

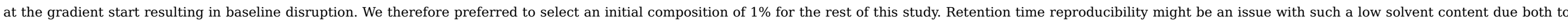

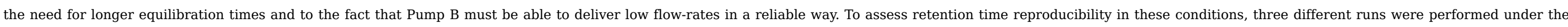

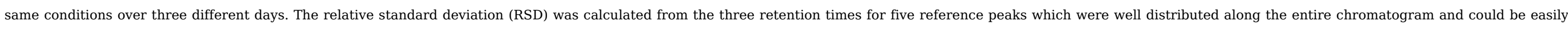

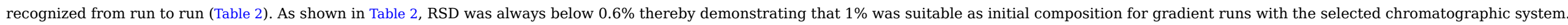

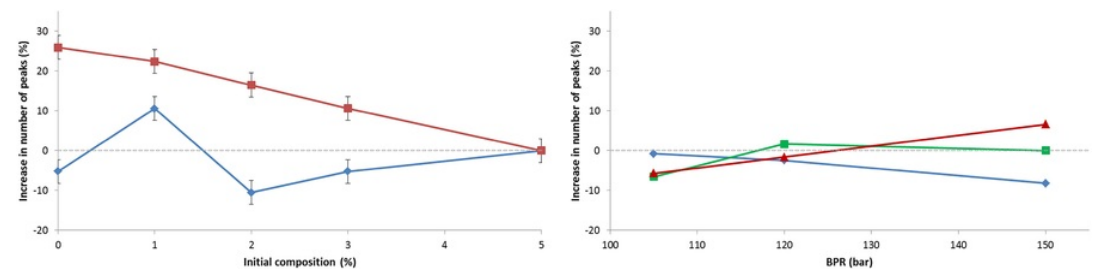

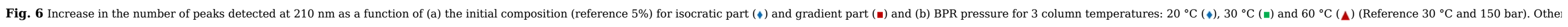

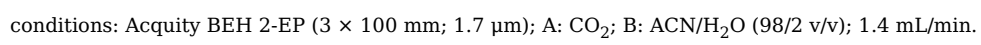


Table 2 RSD of retention times for reference peaks depending on the initial composition of the gradient elution $\left(30{ }^{\circ} \mathrm{C}\right.$ and 150 bar).

alt-text: Table 2

\begin{tabular}{|c|c|c|c|c|c|c|c|c|c|c|}
\hline \multirow[t]{2}{*}{ Initial composition (\%) } & \multicolumn{2}{|c|}{ Peak 1} & \multicolumn{2}{|c|}{ Peak 2} & \multicolumn{2}{|c|}{ Peak 3} & \multicolumn{2}{|c|}{ Peak 4} & \multicolumn{2}{|c|}{ Peak 5} \\
\hline & RSD (\%) & $\operatorname{Tr}(\min )$ & RSD (\%) & $\operatorname{Tr}(\min )$ & RSD (\%) & $\operatorname{Tr}(\min )$ & RSD (\%) & $\operatorname{Tr}(\min )$ & RSD (\%) & $\operatorname{Tr}(\min )$ \\
\hline 5 & 0.27 & 0.70 & 0.16 & 0.92 & 0.48 & 3.08 & 0.41 & 5.61 & 0.53 & 9.47 \\
\hline 1 & 0.29 & 1.08 & 0.52 & 2.57 & 0.19 & 5.52 & 0.27 & 7.89 & 0.15 & 12.48 \\
\hline
\end{tabular}

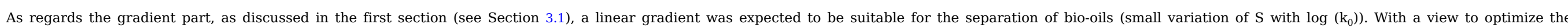

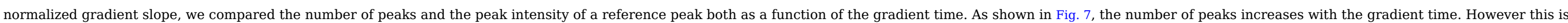

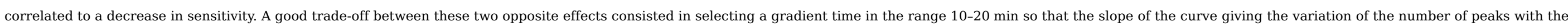
gradient time was not too low. Accordingly, a normalized gradient slope of 0.01 (i.e. a gradient time of 14 min) was selected.

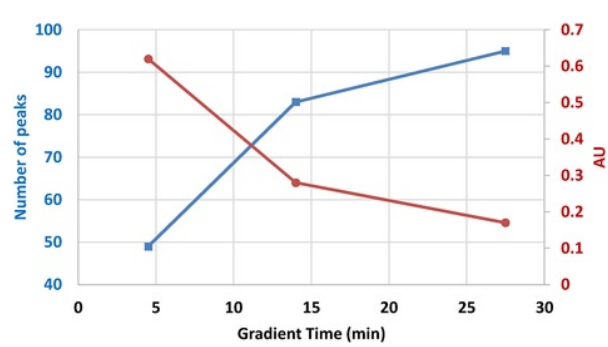

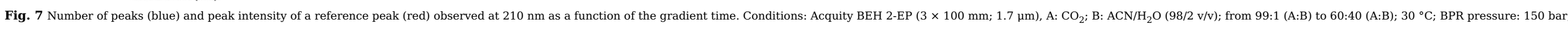
$1.4 \mathrm{~mL} / \mathrm{min}$. (For interpretation of the references to colour in this figure legend, the reader is referred to the web version of this article).

\subsection{Optimization of the column temperature and BPR pressure}

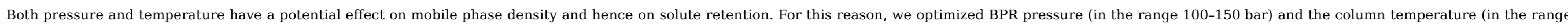

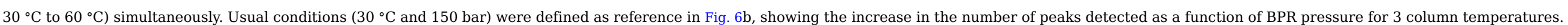

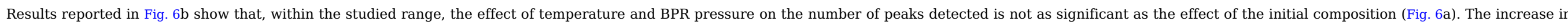

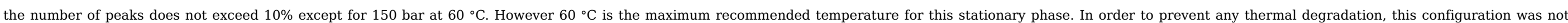

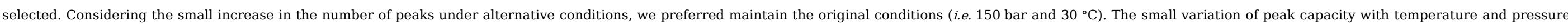

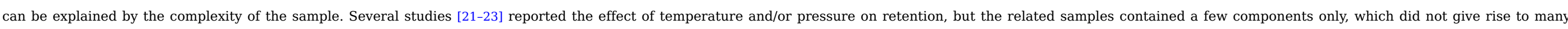

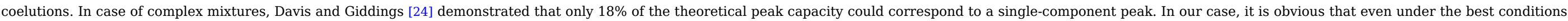

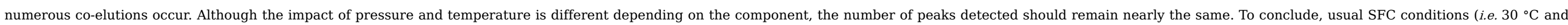
150 bar) seem to be suitable for the analysis of the fast pyrolysis bio-oil.

\subsection{Final SFC-UV method}

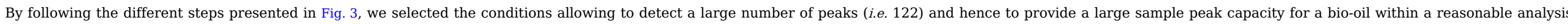

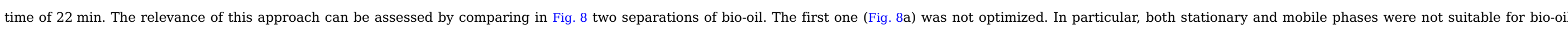

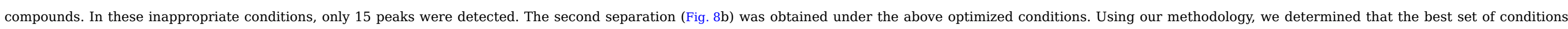




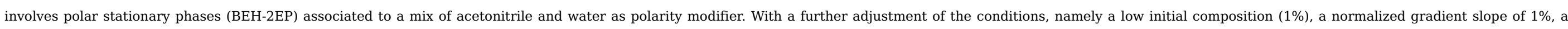
temperature of $30^{\circ} \mathrm{C}$ and BPR pressure of 150 bar, the number of peaks detected in UV (210 nm) was increased to about 120.
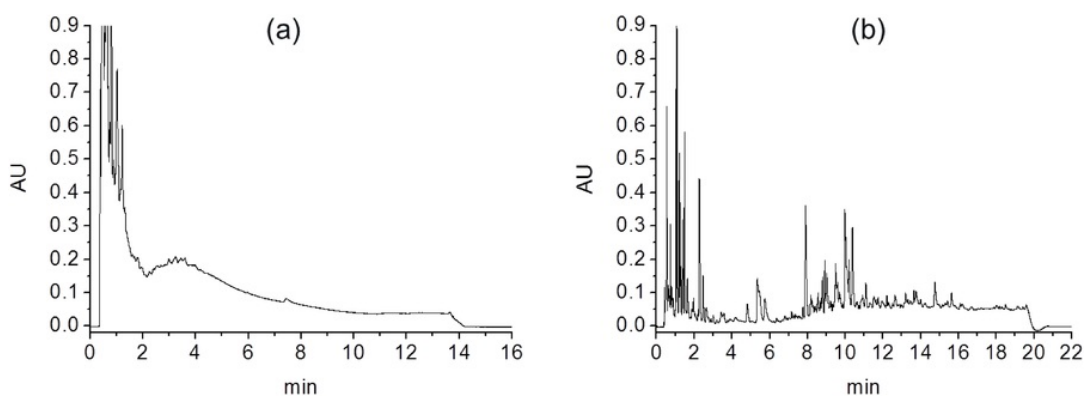

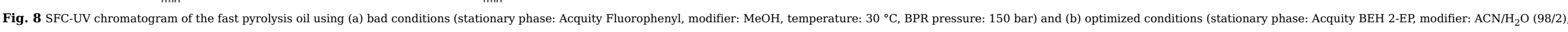
temperature: $30^{\circ} \mathrm{C}$, BPR pressure: $150 \mathrm{bar}$ ).

\section{alt-text: Fig. 8}

\subsection{Hyphenation with MS detection}

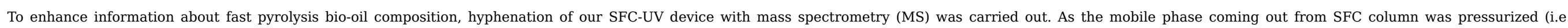

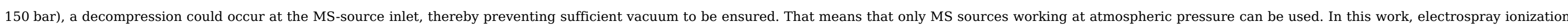
(ESI) and atmospheric pressure chemical ionization (APCI) sources were chosen to cover a large range of polarity and molecular weight.

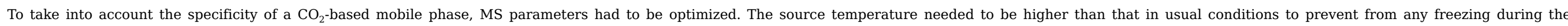

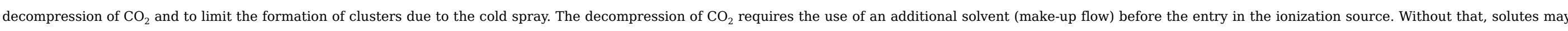

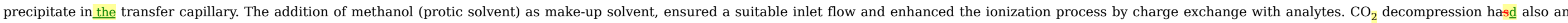
impact on the nebulizing flow. This latter had to be as low as possible to avoid a too wide spray and hence a loss of information. The Fig. 9 illustrates the interface used in both ESI and APCI modes.

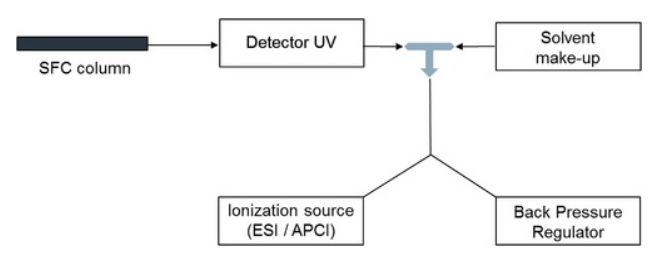

Fig. 9 Schema of interface between SFC-UV and Ionization source of MS.

\section{alt-text: Fig. 9}

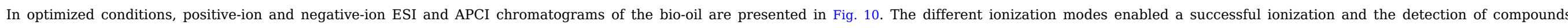

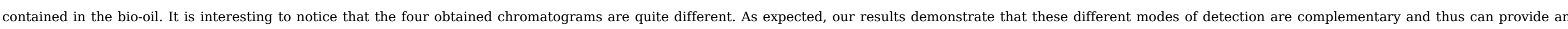

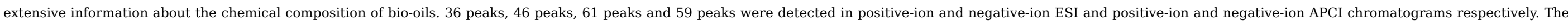

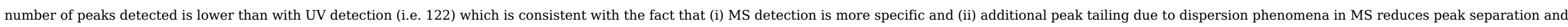
sensitivity (iii) the $210 \mathrm{~nm}$ selected as detection wavelength in the UV allows a much 'broader' detection of compounds. 

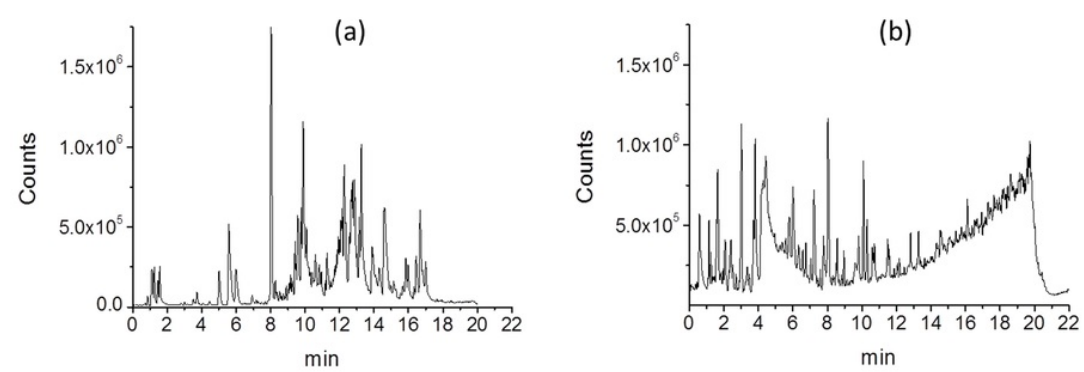

$\min$

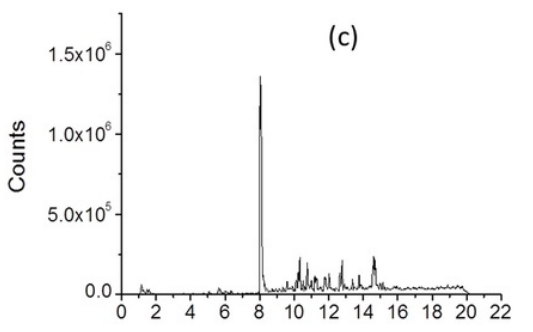

$\min$

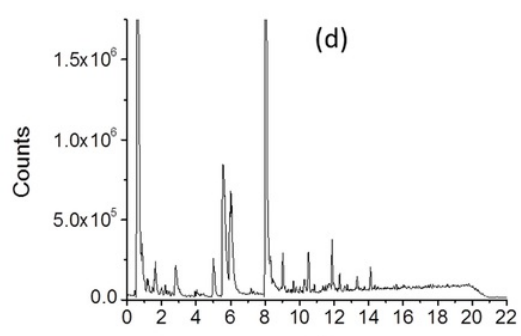

$\min$

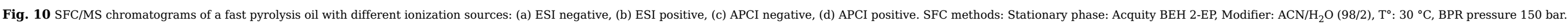
alt-text: Fig. 10

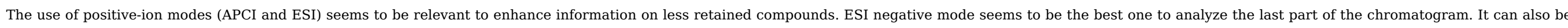

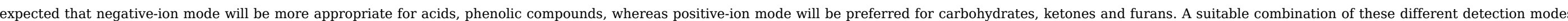
will be required to get an exhaustive information about a large number of all compounds present in bio-oils.

\section{Conclusion}

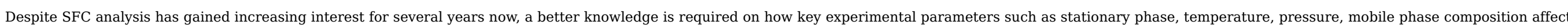

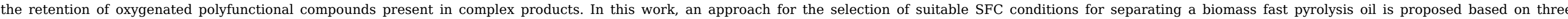

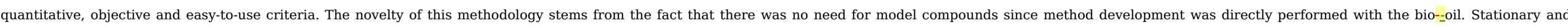
mobile phases, initial mobile phase composition, and gradient slope were optimized in order to achieve a maximum separation power.

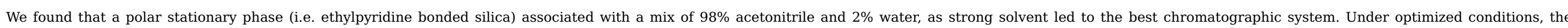

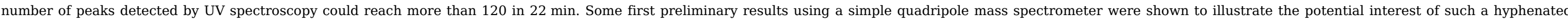
system. To go further on, we analyzed biomass fast pyrolysis oils using a high resolution mass spectrometer (SFC-IT-Tof/MS). Results should be soon submitted in a dedicated paper.

\section{Appendix A. Supplementary data}

Supplementary data associated with this article can be found, in the online version, at http://dx.doi.org/10.1016/j.chroma.2017.06.003.

\section{References}

[1] A.V. Bridgwater, H. Hofbauer and S. van Loo, Thermal Biomass Conversion, 2009

[2] N. Charon, J. Ponthus, D. Espinat, F. Broust, G. Volle, J. Valette and D. Meier, Multi-technique characterization of fast pyrolysis oils, J. Anal. Appl. Pyrolysis 116, 2015 , 18-26.

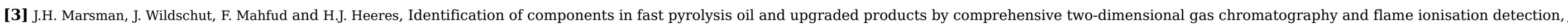


Chromatogr. A 1150, 2007, 21-27.

[4] K. Sipilä, E. Kuoppala, L. Fagernäs and A. Oasmaa, Characterization of biomass-based flash pyrolysis oils, Biomass Bioenerg. 14, 1998, 103-113.

[5] B. Omais, Oxygen Speciation in Coal-Derived Liquids and Upgraded Boi-Oils, 2012.

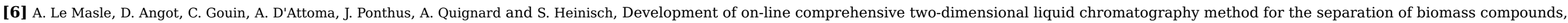
Journal Chromatogr. A 1340, 2014, 90-98.

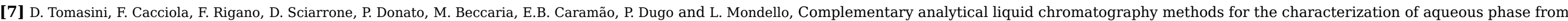
pyrolysis of lignocellulosic biomasses, Anal. Chem. 86, 2014, 11255-11262.

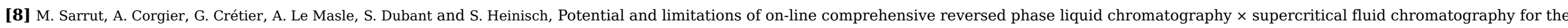
separation of neutral compounds: an approach to separate an aqueous extract of bio-oil, J. Chromatogr. A 1402, 2015, 124-133.

[9] E. Lesellier and C. West, The many faces of packed column supercritical fluid chromatography - A critical review, J. Chromatogr. A 1382, 2015, 2-46.

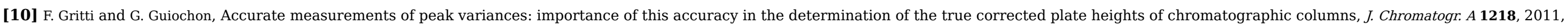
$4452-4461$.

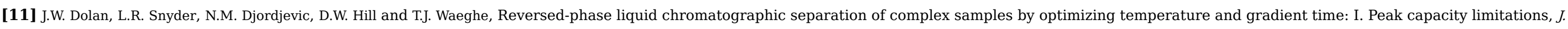
Chromatogr. A 857, 1999, 1-20.

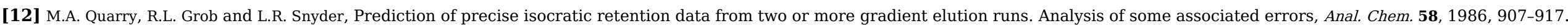

[13] S. Heinisch, J.-L. Rocca and M. Feinberg, Optimization of a chromatographic analysis in reversed phase liquid chromatography, J. Chemometrics 3, 1989, 127-137.

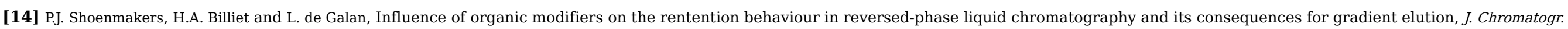
A 185, 1979, 179-195.

[15] J.M. Davis and J.C. Giddings, Statistical theory of component overlap in multicomponent chromatograms, Anal. Chem. 55, 1983, $418-424$.

[16] C. West and E. Lesellier, A unified classification of stationary phases for packed column supercritical fluid chromatography, J. Chromatogr. A 1191, 2008, 21-39.

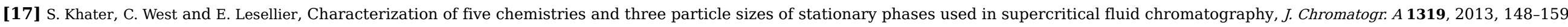

[18] C. West and E. Lesellier, Effects of modifiers in subcritical fluid chromatography on retention with porous graphitic carbon, J. Chromatogr. A 1087, 2005, 64-76.

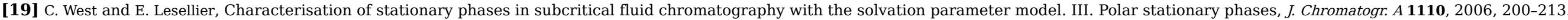

[20] M. Stas, D. Kubic, J. Chudoba and M. Pospís, Overview of analytical methods used for chemical characterization of pyrolysis bio-oil, Energ. Fuels 2014, 385-402

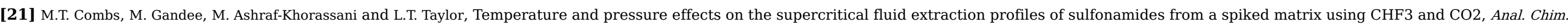
Acta 341, 1997, 285-295.

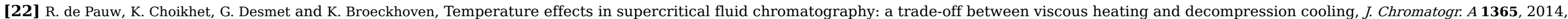
$212-218$.

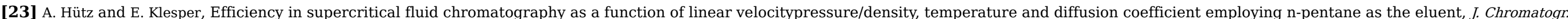
A 607, 1992, 79-89.

[24] J. Davis and C. Giddings, Statistical theory of component overlap in multicomponent chromatograms, Anal. Chem. 55, 1983. 


\section{Appendix A. Supplementary data}

The following are Supplementary data to this article

Multimedia Component 1

\section{Highlights}

- A novel SFC-UV/MS method for the analysis of a biomass fast pyrolysis oil.

- Optimization based on a complex industrial sample using three specific criteria.

- Separation of more than 120 peaks by SFC-UV.

- Complementary information obtained with APCI+/- and ESI+/- modes.

\section{Queries and Answers}

Query: The author names have been tagged as given names and surnames (surnames are highlighted in teal color). Please confirm if they have been identified correctly.

Answer: No, for the second author surname is "Le Masle"

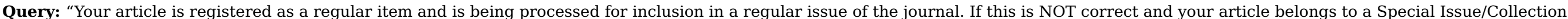
please contact j.kastelein@elsevier.com immediately prior to returning your corrections."

Answer: ok

Query: "u" has been changed to the correct symbol. Please check for the suggestion.

Answer: yes

Query: Please check the presentation of all the equations.

Answer: ok

Query: Section heads have been renumbered and the citation has been changed accordingly. Please check for the correctness.

Answer: ok

Query: Please check the author names in Ref. 24 for the correctness.

Answer: ok

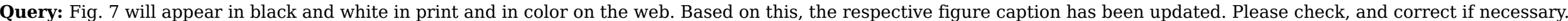
Answer: ok 